\title{
Light-emitting Diodes and the Modulation of Specialty Crops: Light Sensing and Signaling Networks in Plants
}

\author{
Tessa Pocock ${ }^{1}$ \\ Smart Lighting Engineering Research Center, Rensselaer Polytechnic Institute, 110 8th Street, Troy, NY 12180 \\ Additional index words. controlled environment agriculture, photosynthesis, photomorphogenesis
}

\begin{abstract}
The technology to drive the output of individual arrays of light-emitting diodes (LEDs) on timescales down to microseconds is enabling plant scientists and growers control over irradiance- and spectrum-induced plant responses. The two light sensing and signaling networks that regulate desired plant responses involve either photoreceptors (PR) and/or photosynthesis (PSN). These networks control morphological, physiological, and developmental processes (e.g., seed development and germination, seedling development, apical meristem formation, differentiation, flowering, etc.) as well as the energy distribution within the plant. Understanding the individual plant responses and the synergy between the PR and PSN networks will assist in the selection and timing of LED light programs for crop regulation and growth. Both networks sense and respond to irradiance and narrow-band spectra between 350 and $750 \mathrm{~nm}$ although their modes of action are different. Comparing the PR and PSN networks and their effect on plants shows that the PR network primarily regulates developmental processes in new tissues while the PSN network regulates routine operational processes. The two networks are required for healthy plant growth and are reliant on each other for biological fitness. A balance between these two networks will result in greater plant efficacy and can be achieved by light programs whose irradiance, spectra, duration, and timing can be regulated. Replacing high-intensity discharge (HID) lamps with LEDs is a catalyst for a fundamental change in plant lighting and we are on a steep learning curve to fully realize how to fully control LED technology in plant growth applications.
\end{abstract}

Light is an absolute requirement for plant growth and development. It is important as it elicits photosynthetic, photomorphogenic, photodamaging, mutagenetic, and thermal effects. Plants have evolved long- and short-term acclimation mechanisms that function to maintain photostasis in naturally fluctuating environments, including light. Used frequently now in human applications, LEDs are a disruptive innovation in horticulture and the ability to rapidly control the spectrum, duration, and intensity is truly novel. LED lighting systems have opened up a new field of dynamic research for plant scientists, horticulturists, and luminaire manufacturers. International large-scale horticultural research on the benefits of using LEDs in horticulture began in 2009-10 and was primarily led by commercial luminaire manufacturers. Since then, interest has increased in 1) use of mercury-free LEDs to replace or complement HID lamps [includes highpressure sodium (HPS) and mercury vapor lamps] for greenhouse supplemental lighting; 2) development of lighting strategies for high-density vertical farming; 3) the use of electric lights as the sole light source for high-value specialty crops such as medicinal plants; and 4) the ability to regulate and

Received for publication 4 Dec. 2014. Accepted for publication 9 Mar. 2015.

This work was supported primarily by the Engineering Research Centers Program (ERC) of the National Science Foundation (NSF) under NSF Cooperative Agreement No. EEC-0812056 and in part by New York State under NYSTAR contract C090145 and NYSERDA contract J50562. Thanks to Neil Mattson and Stefan Falk for their reviews of this manuscript and lively discussions.

This paper was presented as part of the Colloquium entitled, "The Importance of Light Quality for High Value Plant Products," 28-31 July 2014, during the ASHS Annual Conference in Orlando, FL.

${ }^{1}$ Corresponding author. E-mail: pococt@rpi.edu. control plant biochemical, developmental, and morphological characteristics. The control of LED lighting in horticulture goes beyond on or off and their adjustability can be used to regulate desirable plant processes while maintaining good yield and reducing energy use.

Growing crops that have been selected to grow well under HPS lighting under LED fixtures with a very different spectrum is challenging. Our current state of knowledge of plant growth responses under LEDs represents a collection of single observations as irradiance, spectral ratios, and peak maxima differ between the LEDs used in the various studies. Therefore, it is difficult to prescribe the perfect light for "optimal" growth. Light is a trigger for many plant processes and particularly when used dynamically can result in 1) changes in the developmental programs (i.e., seedling, juvenile, adult, flowering stages) and 2) immediate physiological acclimation responses to the environment (i.e., stress tolerance, pigment and secondary metabolite synthesis) (Gutschick and BassiriRad, 2003). Light-inducible sensing and signaling networks are present in plants and thus, plant acclimation responses can be engaged to promote and shape PSN and photomorphogenesis. The plant attributes modulated by either irradiance or spectrum and the responsible lightsensing networks are presented here with the aim of assisting in the development of LED lighting algorithms. From a practical standpoint, crop yield, nutrient composition, flowering, plant height, and tolerance to biotic (environmental) and abiotic (pest/disease) stresses, among others, can be modulated by light and would increase overall crop quality.

\section{PLANT SENSING AND SIGNALING NETWORKS}

Light intensity, spectral distribution, and long- and short-term fluctuating light can alter plants considerably. The two primary light sensing and signaling networks are the following: 1) PR-mediated photomorphogenic responses (Möglich et al., 2010) and 2) PSN (Pfalz et al., 2012).

$P R$ sensing and signaling. Photoreceptor sensing and signaling networks play a major role in developmental programs that generate new tissues (Pfalz et al., 2012). Three different PR classes have been identified in plants based on the chemical nature and photochemistry of their chromophores: 1) phytochromes (PHY); 2) cryptochromes (CRY); and 3) lightoxygen-voltage sensors (LOV), which include phototropin (PHO) and zeitlupe (ZTL) (Chen et al., 2004; Möglich et al., 2010). Each PR class preferentially absorbs and is activated by specific narrow bands in different regions of the spectrum (Möglich et al., 2010). Although some physiological responses are triggered by only one PR, many responses are the result of coordination and crosstalk between them (Franklin and Quail, 2010; Kami et al., 2010).

The first PR class, PHY, senses the ratio of red and far red (FR) light (Casal 2000; Chen and Chory, 2011; Franklin and Quail, 2010). The biologically inactive $\mathrm{P}_{\mathrm{r}}$ form is synthesized in the dark and is converted to $\mathrm{P}_{\mathrm{fr}}$ within 1 to $2 \mathrm{~min}$ in the presence of red light (660 $670 \mathrm{~nm}$ ) (Chen and Chory, 2011). The conversion to $\mathrm{P}_{\mathrm{fr}}$ is reversible by FR light $(725-735 \mathrm{~nm})$ and therefore, red and FR light act as rapid molecular switches (Smith and Whitelam, 1997). The use of mutants has led to the elucidation of many of the specific responses attributed to each of the phytochrome A-E (PHY A-E) variants (reviewed in Franklin and Quail, 2010). The PHY sensor system influences a large number of plant developmental processes including seed germination (Casal and Sanchez,1998), de-etiolation (Franklin and Quail, 2010), shade avoidance and plant height (Franklin, 2008), branching (Leduc et al., 2014), stomatal development (Casson and Hetherington, 2010), photoperiodic responses and flowering (Thomas, 2006), circadian clock (Devlin and Kay, 2000), plant 
immunity (herbivores/pathogens) (Ballaré, 2014), and freezing tolerance (Franklin and Whitelam, 2007) (Table 1).The second PR class is the blue light ( $380-470 \mathrm{~nm})$ absorbing CRYs (Ahmed et al., 2002; Möglich et al., 2010). Interestingly, CRYs are ubiquitous across all of the kingdoms ( $\mathrm{Li}$ and Yang, 2007; Lin and Todo, 2005). They can be turned on in seconds and off within $5 \mathrm{~min}$ (Tischer and Weiner, 2014). CRYs are involved in the control of seed dormancy and germination (Barrero et al., 2014), de-etiolation (Ahmed and Cashmore, 1993), circadian clock (Devlin and Kay, 2000; Somers et al., 1998), anthocyanin biosynthesis (Ahmed et al., 1995), floral initiation (Koorneef et al., 1998; Lin, 2000), branching (Leduc et al., 2014), and stomatal opening (Sellaro et al., 2010) (Table 1). Light-oxygen-voltage sensors detect blue light as well. Phototropin (PHO) and ZTL families of PR use LOV domains whose activity peaks at 425,450 , and $470 \mathrm{~nm}$ when in the dark-adapted state (Briggs and Christie, 2002). Phototropins 1 and 2 mediate a number of fast plant responses that include phototropism, chloroplast and leaf movements, and stomatal opening (Briggs and Christie, 2002; Suetsugu and Wada, 2013). The ZTL family controls plant responses that are on a slower time scale and are primarily involved in entrainment of the circadian clock and time to flower (Demarsy and Fankhauser, 2009). Green light (500-600 nm) causes responses although no specific PR has been found to date. Green light is sensed by the plant as shade and induces shade morphology similar to the well-known PHY shade-avoidance response (Zhang et al., 2011). Furthermore, green light reverses CRY activity and there is evidence now that CRY not only senses blue light but senses and responds to changes in the blue to green ratio (Bouly et al., 2007; Sellaro et al., 2010). Green light responses are enhanced under low light conditions as is found in northern greenhouses during the darker months (Wang and Folta, 2013). The PR sensing and signaling system is complex as there is coaction between the different PR classes (Casal, 2000). The presence of PR-activating spectral regions in horticulture LED fixtures is necessary for full control of desired plant responses described above. Plant responses that are under control of the PR network are summarized in Table 1 .

Photosynthetic sensing and signaling. In addition to the PR network, plants sense light intensity and spectral ratios through PSN and is referred to as the PSN sensing and signaling network (Pfannschmidt et al., 1999; Zachgo et al., 2013). Photosynthesis is highly regulated as plant survival and fitness depends on it and its efficiency underlies all plant functions including photomorphogenesis. There are several PSN light acclimation mechanisms and their primary function is to maintain photosynthetic efficiency at the highest levels possible (Pfannschmidt, 2003). One of the first described PSN sensing and signaling components is the plastoquinone (PQ) pool (Foyer et al., 2012; Hüner et al., 1998; Pfalz et al., 2012). Plastoquinone picks up two electrons at photosystem II (PSII) and transports them through the thylakoid membrane to the cytochrome $b_{6} f$ complex after which they

Table 1. Plant responses to light and the sensing and signaling networks involved. The photoreceptor (PR) network involves light absorption by phytochromes (PHY), cryptochromes (CRY) and the light oxygen voltage PRs, phototropin (PHO), and zeitlupe (ZTL). The photosynthesis (PSN) sensing and signaling network involves the redox state of plastoquinone $(\mathrm{PQ})$, the proton motive force $(\Delta \mathrm{pH})$, the redox state of ferredoxin and thioredoxin $(\mathrm{F} / \mathrm{T})$ and the production of reactive oxygen species (ROS). The light effectors are high light (HL, $>500 \mu \mathrm{mol}$ photon $\left./ \mathrm{m}^{2} / \mathrm{s}\right)$, blue light (B, 400-500 nm), green light (G, 500-600 nm), red light (R, 600-700 nm), and far red light (FR, 700-750 nm). CRYg indicates the G light absorbing variant of CRY.

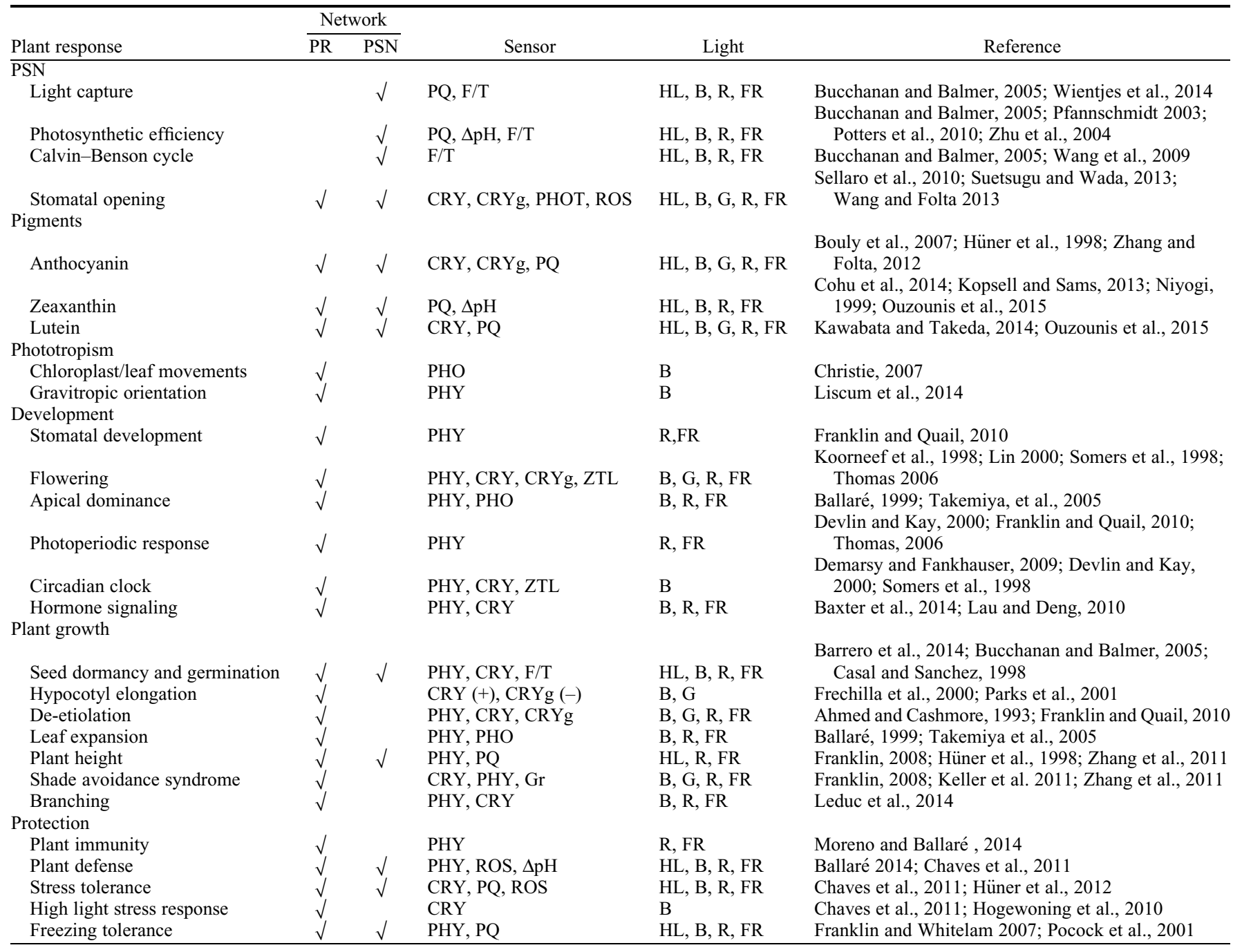


are picked up by mobile plastocyanin and delivered through the lumen to photosystem I (PSI) where they reduce $\mathrm{NADP}^{+}$into NADPH that is used to reduce carbon dioxide into carbohydrates. The reduction-oxidation (redox) state of the PQ pool senses and signals if adjustments need to be made to maintain photosynthetic efficiency and prevent photodamage (Pfannschmidt, 2003). It is measured as the photochemical quenching of chlorophyll $a$ fluorescence and is expressed as $\mathrm{q}_{\mathrm{P}}$ and $\mathrm{q}_{\mathrm{L}}$ or $1-\mathrm{q}_{\mathrm{P}}$ and $1-\mathrm{q}_{\mathrm{L}}$ (Hüner et al., 2012). Growth under conditions where the PQ pool is reduced has practical applications as it can increase freezing tolerance (Pocock et al., 2001), modulate plant height (Hüner et al., 1998), and increase nutritive qualities (Cohu et al., 2014) among others (Table 1). Furthermore, the PQ pool senses spectral ratios and can be "activated" (reduced) when the spectral distribution is below $680 \mathrm{~nm}$ and "deactivated" (oxidized) under a spectral distribution up to $700 \mathrm{~nm}$ and beyond (FRenriched). Photosystems I and II work together and through them light energy is converted to chemical energy which is required for plant growth. Energy imbalances can occur between the two photosystems during periods of high light or changes in the spectrum and state transitions occur which help maintain PSN (Allen et al., 1981; Tikkanen and Aro, 2012). State transitions are a short-term acclimation mechanism that involves phosphorylation and migration of light-harvesting complexes between the two photosystems (Allen, 1992). Changes in the spectra can induce state transitions as PSII absorbs wavelengths of $680 \mathrm{~nm}$ and below while PSI absorbs wavelengths up to $700 \mathrm{~nm}$. Under fullspectrum sunlight in a greenhouse, both photosystems are working as their preferential wavelengths are present (Allen, 1992). How does this correlate with the use of LED lighting in plant growth? By definition, plants grown under HPS or fluorescent bulbs are growing under what can be considered PSI light while blue and red LEDs provide a PSII light environment. During northern, dark winters, or in closed environments with no daylight, plants grown under blue and red LED spectra are never exposed to wavelengths over $680 \mathrm{~nm}$ and PSII will be preferentially excited relative to PSI for their entire life cycle. This never occurs in nature. Whether plants grown under PSII light alone possess long-term acclimation mechanisms remains to be determined.

The acidification of the lumen $(\Delta \mathrm{pH})$ during PSN also senses changes in light, regulates electron transport, and modulates nonphotochemical quenching (NPQ) in PSII (Foyer et al., 2012; Kono and Terashima, 2014). The photoprotective xanthophyll cycle is a significant component of NPQ and involves the increase in zeaxanthin concentrations within the plant, an important dietary nutrient for eye health (Cohu et al., 2014; Niyogi, 1999; Semba and Dagnelie, 2003). $\Delta \mathrm{pH}$ and NPQ are reversed in the dark and this sensing system is considered to be primarily a response to fluctuating and high light rather than light quality (Tikkanen et al., 2010). However, it has been recently reported that orchids (Phalaenopsis hybrid 'Vivien' and 'Purple Star') growing under natural shaded light with supplemental $40 \%$ blue and $60 \%$ red LEDs resulted in higher NPQ and lutein concentrations (Ouzounis et al., 2015). Adjusting the intensity, spectrum, and timing of LEDs offers a way to increase crop nutritive value through the regulation of $\Delta \mathrm{pH}$ and the resulting NPQ (Cohu et al., 2014). The ferredoxin/thioredoxin $(\mathrm{F} / \mathrm{T})$ system is a light sensor that is linked to PSI. In plants, it has been found to regulate 43 proteins and 15 physiological processes (Bucchanan and Balmer, 2005). The F/T system is activated by high light or preferential excitation of PSI (FR) relative to PSII (blue-red) and is primarily involved in the regulation of PSN. For a long time, reactive oxygen species (ROS) were solely associated with light-induced oxidative stress (Baxter et al., 2014; Mittler et al., 2011). It is now accepted that ROS is a PSN-induced redox signaling molecule that regulates protective responses against pathogens in plants (Lehmann et al., 2014). ROS signaling can be induced by high light where there is unbalanced energy flow through the photosystems to metabolism. Thus there are many photosynthetic components that are light sensors that signal responses that maintain the day-to-day operations of PSN. Plant responses that are under control of the PSN network are summarized in Table 1.

\section{TYING THE TWO SENSING AND SIGNALING NETWORKS TOGETHER: HOW TO MODULATE PLANTS WITH LEDS?}

Plants show a high degree of plasticity in their acclimation processes under different light conditions. Increasing our understanding of the physiological light effects on longor short-term crop production will enable full use of LED lighting technology. The presence of two, sometimes redundant, light sensing and signaling networks in plants adds complexity. There is coordination between the two sensing and signaling networks and three themes have emerged. First, the PSN sensing and signaling network is predominant in, and required for, day-to-day operations (operational) and, in addition, provides all of the energy required by the PR network. Second, the PR sensing and signaling network is predominantly active in phototropism, development, and plant growth. Third, all regions of the spectrum $(400-750 \mathrm{~nm})$ are involved in the induction of plant responses by both sensing networks. The regulation of plant pigment concentrations and tolerance to biotic and abiotic stresses can be induced through the activation of either network and the primary "active" regions of the spectrum involved in these responses are blue, red, and FR while green light appears to reverse these processes.

Determining best practices for the use of LED systems in plant growth applications is accelerating through the understanding of these sensing and signaling processes as well as their outcomes. The possibilities of regulating plant attributes with light are staggering and although much is known it has only just begun. The question often arises on how LED technology will shape controlled environment agriculture in the future. The ability to quickly regulate light-induced pathways by tuning intensity, spectrum, duration, and timing (pulse width modulation) of narrow band LEDs is here now.

\section{Literature Cited}

Ahmed, M. and A.R. Cashmore. 1993. HY4 gene of $A$. thaliana encodes a protein with characteristics of a blue-light photoreceptor. Nature 366:162-166.

Ahmed, M., C. Lin, and A.R. Cashmore. 1995. Mutations throughout an Arabidopsis blue-light photoreceptor impair blue-light-responsive anthocyanin accumulation and inhibition of hypocotyl elongation. Plant J. 8:653-658.

Ahmed, M., N. Grancher, M. Heil, R.C. Black, B. Giovani, P. Galland, and D. Lardemer. 2002. Action spectrum for cyptochrome-dependent hypocotyl growth inhibition in Arabidopsis. Plant Physiol. 129:774-785.

Allen, J.F. 1992. How does protein phosphorylation regulate photosynthesis? Trends Biochem. Sci. 17:12-17.

Allen, J.F., J. Bennett, E. Steinback, and C.J. Arntzen. 1981. Chloroplast protein phosphorylation couples plastoquinone redox state to distribution of excitation energy between photosystems. Nature 291:25-29.

Ballaré, C.L. 1999. Keeping up with the neighbours: Phytochrome sensing and other signalling mechanisms. Trends Plant Sci. 14:97-102.

Ballaré, C.L. 2014. Light regulation of plant defense. Annu. Rev. Plant Biol. 65:335-363.

Barrero, J.M., A.B. Downie, Q. Xu, and F. Gubler. 2014. A role for barley cryptochrome 1 in light regulation of grain dormancy and germination. Plant Cell 26:1094-1104.

Baxter, A., R. Mittler, and N. Suzuki. 2014. ROS as key players in plant stress signalling. J. Expt. Bot. 65:1229-1240

Bouly, J.-P., E. Schleicher, M. Dionisio-Sese, F. Vandenbussche, D. Van der Straeten, N. Bakrim, S. Meier, A. Batschauer, P. Galland, R. Bitti, and M. Ahmad. 2007. Cryptochrome blue light photoreceptros are activated through interconversion of flavin redox states. J. Biol. Chem. 282:9383-9391.

Briggs, W.R. and J.M. Christie. 2002. Phototropins 1 and 2: Versatile blue-light receptors. Trends Plant Sci. 7:204-210

Bucchanan, B.B. and Y. Balmer. 2005. Redox regulation: A broadening horizon. Annu. Rev. Plant Biol. 56:187-220.

Casal, J.J. 2000. Phytochromes, cryptochromes, phototropin: Photoreceptor interactions in plants. Photochem. Photobiol. 71:1-11.

Casal, J.J. and R.A. Sánchez. 1998. Phytochromes and seed germination. Seed Sci. Res. 8:317329

Casson, S.A. and A.M. Hetherington. 2010. Environmental regulation of stomatal development. Curr. Opin. Plant Biol. 13:90-95.

Chaves, I., R. Pokorny, M. Byrdin, N. Hoang, T.J. van der Horst, A. Batschauer, and M. Ahmad. 2011. The cryptochromes: Blue light photoreceptors in plants and animals. Annu. Rev. Plant Biol. 62:335-364.

Chen, M. and J. Chory. 2011. Phytochrome signalling mechanisms and the control of plant development. Trends Cell Biol. 21:664-671.

Chen, M., J. Chory, and C. Fankhauser. 2004 Light signal transduction in higher plants. Annu. Rev. Genet. 38:87-117. 
Christie, J.M. 2007. Phototropin blue-light receptors. Annu. Rev. Plant Biol. 58:21-45.

Cohu, C.M., E. Lombardi, W.W. Adams, III, and B. Demmig-Adams. 2014. Increased nutritional quality of plants for long-duration spaceflight missions through choice of plant variety and manipulation of growth conditions. Acta Astronaut. 94:799-806.

Demarsy, E. and C. Fankhauser. 2009. Higher plants use LOV to perceive blue. Curr. Opin. Plant Biol. 12:69-74.

Devlin, P.F. and S.A. Kay. 2000. Cryptochromes are required for phytochrome signaling to the circadian clock but not for rhythmicity. Plant Cell 12:2499-2510.

Foyer, C.H., J. Neukermans, G. Queval, G. Noctor, and J. Harbinson. 2012. Photosynthetic control of electron transport and the regulation of gene expression. J. Expt. Bot. 63:1637-1661.

Franklin, K.A. 2008. Shade avoidance. New Phytol. 179:930-944.

Franklin, K.A. and G.C. Whitelam. 2007. Lightquality regulation of freezing tolerance in Arabidopsis thaliana. Nat. Genet. 39:1410-1413.

Franklin, K.A. and P.H. Quail. 2010. Phytochrome functions in Arabidopsis development. J. Photochem. Photobiol. 61:11-24.

Frechilla, S., L.D. Talbott, R.A. Bongomolni, and E. Zeiger. 2000. Reversal of blue light-stimulated stomatal opening by green light. Plant Cell Physiol. 41:171-176.

Gutschick, V.P. and H. BassiriRad. 2003. Extreme events as shaping physiology, ecology, and evolution of plants: Toward a unified definition and evaluation of their consequences. New Phytol. 160:21-42.

Hogewoning, S.W., G. Trowborst, H. Maljaars, H. Poorter, W. van Ieperen, and J. Harbinson. 2010. Blue light dose-response of leaf photosynthesis, morphology, and chemical composition of Cucumis sativus grown under different combinations of red and blue light. J. Expt. Bot. 61:3107-3117.

Hüner, N.P.A., R. Bode, K. Dahal, L. Hollis, D. Rosso, M. Krol, and A.G. Ivanov. 2012. Chloroplast imbalance governs phenotypic plasticity: The "grand design of photosynthesis" revisited. Front. Plant Sci. 3:255.

Kami, C., S. C. Lorrain, P. Hornitschek, and C. Fankhauser. 2010. Light-regulated plant growth and development. Curr. Top. Dev. Biol. 91:29-66.

Kawabata, Y. and S. Takeda. 2014. Regulation of xanthophyll cycle pool size in response to high light irradiance in Arabidopsis. Plant Biotechnol. 31:229-240.

Keller, M.M., Y. Jaillais, U.V. Pedmale, J.E. Moreno, J. Chory, and C.L. Ballaré. 2011. Cryptochrome 1 and phytochrome B control shade-avoidance responses in Arabidopsis via independent hormonal cascades. Plant J. 67:195207.

Kono, M. and I. Terashima. 2014. Long-term and short-term responses of the photosynthetic electron transport to fluctuating light. J. Photochem. Photobiol. B 137:89-99.

Koorneef, M., C. Alonso-Blanco, A.J.M. Peeters, and W. Soppe. 1998. Genetic control of flowering time in Arabidopsis thaliana. Annu. Rev. Plant Physiol. Plant Mol. Biol. 49:345-370.

Kopsell, D.A. and C.E. Sams. 2013. Increases in shoot tissue pigments, glucosinolates, and mineral elements in sprouting broccoli after exposure to short-duration blue light from light emitting diodes. J. Amer. Soc. Hort. Sci. 138:31-37.

Lau, O.S. and X.W. Deng. 2010. Plant hormones signaling lightens up: Integrators of light and hormones. Curr. Opin. Plant Biol. 13:571-577.

Leduc, N., H. Roman, F. Barbier, T. Péron, L. Huché-Thélier, J. Lothier, S. Demotes-Mainard, and S. Sakr. 2014. Light signaling in bud outgrowth and branching in plants. Planta 3:223-250.

Lehmann, S.M., Serrano, F.L. Haridon, S.E. Tjamos, and J.-P. Metraus. 2014. Reactive oxygen species and plant resistance to fungal pathogens. Phytochemistry 112:54-62.

Li, Q.-H. and H.-Q. Yang. 2007. Cryptochrome signaling in plants. Photochem. Photobiol. 83:94 101.

Lin, C. 2000. Photoreceptors and regulation of flowering time. Plant Physiol. 123:39-50.

Lin, C. and T. Todo. 2005. The cryptochromes. Genome Biol. 6:220-229.

Liscum, E., S.K. Askinosie, D.L. Leuchtman, J. Morrow, K.T. Willenburg, and D.R. Coats. 2014. Phototropism: Growing towards and understanding of plant movement. Plant Cell 26:38-55.

Mittler, R., S. Vanderauwera, N. Suzuki, G. Miller, V.B. Tognetti, K. Vanderpoele, M. Gollery, V. Shulaev, and F. Van Breusegem. 2011. ROS signaling: The new wave? Trends Plant Sci. 16:300-309.

Moreno, J.E. and C.L. Ballaré. 2014. Phytochrome regulation of plant immunity in vegetation crops. J. Chem. Ecol. 40:848-857.

Möglich, A., X. Yang, R.A. Ayers, and K. Moffat. 2010. Structure and function of photoreceptors. Annu. Rev. Plant Biol. 61:21-47.

Niyogi, K.K. 1999. Photoprotection revisited: Genetic and molecular approaches. Annu. Rev. Plant Physiol. Plant Mol. Biol. 50:333-359.

Ouzounis, T., Z. Fretté, C.-O. Ottosen, and E. Rosenqvist. 2015. Spectral effects of LEDs on chlorophyll fluorescence and pigmentation in Phalaenopsis 'Vivien' and 'Purple Star'. Physiol. Plant., doi: 10.1111/ppl.12300.

Parks, B.M., K.M. Folta, and E.P. Spalding. 2001. Photocontrol of stem growth. Curr. Opin. Plant Biol. 4:436-440.

Pfalz, J., M. Liebers, M. Hirth, B. Grübler, Y. Schröter, L. Dietzel, and T. Pfannschmidt. 2012. Environmental control of plant nuclear gene expression by chloroplast redox signals. Front. Plant Sci. 3:257-266.

Pfannschmidt, T. 2003. Chloroplast redox signals: How photosynthesis controls its own genes. Trends Plant Sci. 8:33-41.

Pfannschmidt, T., A. Nilsson, and J.F. Allen. 1999 Photosynthetic control of chloroplast gene expression. Nature 397:625-628.

Pocock, T., V. Hurry, L.V. Savitch, and N.P.A. Hüner. 2001. Susceptibility to low-temperature photoinhibition and the acquisition of freezing tolerance in winter and spring wheat: The role of growth temperature and irradiance. Physiol. Plant. 113:499-506.
Potters, G., N. Horemans, and M.A.K. Jansen. 2010. The cellular redox state in plant stress biology. Plant Physiol. Biochem. 48:292-300.

Sellaro, R., M. Crepy, S.A. Trupkin, E. Karayekov, A.S. Buchovsky, C. Rossi, and J.J. Casal. 2010. Cryptochrome as a sensor of the blue/green ratio of natural radiations in Arabidopsis. Plant Physiol. 154:401-409.

Semba, R.D. and G. Dagnelie. 2003. Are lutein and zeaxhanthin conditionally essential nutrients for eye health? Med. Hypotheses 61:464-472.

Somers, D.E., P.F. Devlin, and S.A. Kay. 1998. Phytochromes and cryptochromes in the entrainment of the Arabidopsis circadian clock. Science 282:1488-1490.

Smith, H. and G.C. Whitelam. 1997. The shade avoidance syndrome: Multiple responses mediated by multiple phytochromes. Plant Cell Environ. 20:840-844.

Suetsugu, N. and M. Wada. 2013. Evolution of three LOV blue light receptor families in green plants and photosynthetic stramenophiles: Phototropin, ZTL/FKF1/LKP2 and aureochrome. Plant Cell Physiol. 54:8-23.

Takemiya, A., S.-I. Inoue, M. Doi, T. Kinoshita, and K.-I. Shimazaki. 2005. Phototropins promote plant growth in response to blue light in low light environments. Plant Cell 17:1120-1127.

Thomas, B. 2006. Light signals and flowering. J. Expt. Bot. 57:3387-3393.

Tikkanen, M. and E.-M. Aro. 2012. Integrative regulatory network of plant thylakoid energy transduction. Trends Plant Sci. 19:10-17.

Tikkanen, M., M. Grieco, S. Kangasjärvi, and E.-M. Aro. 2010. Thylakoid protein phosphorylation in higher plant chloroplasts optimizes electron transfer under fluctuating light. Plant Physiol 152:723-735.

Tischer, D. and O.D. Weiner. 2014. Illuminating cell signalling with optogenetic tools. Mol. Cell Biol. 15:551-558.

Wang, H., M. Gu, J. Cui, K. Shi, Y. Zhou, and J. Yu. 2009. Effects of light quality on $\mathrm{CO}_{2}$ assimilation, chlorophyll-fluorescence quenching, expression of Calvin cycle genes and carbohydrate accumulation in Cucumis sativus. J. Photochem. Photobiol. B 96:30-37.

Wang, Y. and K.M. Folta. 2013. Contributions of green light to plant growth and development. Amer. J. Bot. 100:70-78.

Wientjes, E., H. van Amerongen, and R. Croce. 2014. Quantum yield of charge separation in photosystem II: Functional effect of changes in the antenna size upon light acclimation. J. Phys. Chem. B 117:11200-11208.

Zachgo, S., G.T. Hanke, and R. Scheibe. 2013. Plant cell microcompartments: A redox-signaling perspective. Biol. Chem. 394:203-216.

Zhang, T., S.A. Maruhnich, and K.M. Folta. 2011. Green light induces shade avoidance symptoms. Plant Physiol. 157:1528-1536.

Zhang, T. and K.M. Folta. 2012. Green light signalling and adaptive response. Plant Signal. Behav. 7:1-4

Zhu, X.G., D.R. Ort, J. Whitmarsh, and S.P. Long. 2004. The slow reversibility of photosystem II thermal energy dissipation on transfer form high to low light may cause large losses in carbon gain by crop canopies: A theoretical analysis. J. Expt. Bot. 55:1167-1175. 